\title{
The Impact of Price Bundling on the Evaluation of Bundled Products: Does It Matter How You Frame It?
}

\author{
Anjulie Hähnchen ${ }^{1}$ Bernhard Baumgartner² ${ }^{2}$
}

Received: 13 January 2017 / Accepted: 7 January 2020 / Published online: 31 January 2020

(C) The Author(s) 2020

\begin{abstract}
Companies often sell their products in a price bundle at a discount. These discounts can be presented to consumers in various ways.

Past studies have predominantly focused on the short-term effects of various price reduction frames within bundle offers. The primary purpose of this paper is to investigate the post-promotion effects of presenting a product within differently framed price bundles on consumers' assessment of this product.

A choice-based conjoint design is applied to investigate purchase probability and willingness to pay. The results of the study indicate, among other findings, that the evaluation of a product can deteriorate if this product is presented in a price bundle and that this effect depends on the framing of price discounts in the bundle.
\end{abstract}

Keywords Price discount framing $\cdot$ Bundling $\cdot$ Conjoint $\cdot$ Post-promotion effect

\section{Introduction}

Bundling, the joint selling of two or more products in a package, is a common practice in marketing. Well-known examples are body lotion and perfume or meal deals in fast food restaurants.

\footnotetext{
A. Hähnchen

anjulie-haehnchen@gmx.de

$\triangle$ B. Baumgartner

bebaumga@uos.de

1 BSL Transportation Consultants, 20457 Hamburg, Germany

2 Department of Marketing, University of Osnabrueck, 49069 Osnabrueck, Germany
} 
The term "price bundling" refers to the popular approach of offering a discount on the bundle components or the bundle as a whole (Stremersch and Tellis 2002). Price bundling is so widespread that consumers may even infer savings when no discount information is presented for the bundle (Heeler et al. 2007). Estelami (1999) finds that, on average, a consumer can save approximately $8 \%$ by buying a bundle consisting of complementary products. Bundling is therefore widely used as a promotion tool.

Research conducted in bundling and non-bundling contexts shows that promotions generally enhance short-term purchases (Foubert and Gijsbrechts 2007; Blattberg and Neslin 1989; Blattberg et al. 1995). However, in addition to these positive shortterm effects, promotions might have negative long-term effects, which reduce postpromotion choice. For stand-alone products, previous research reveals that promoted products exhibit lower perceived quality (Nusair et al. 2010; Raghubir and Corfman 1999), a lower reference price (e.g., Blattberg et al. 1995; Diamond and Campbell 1989), lower future price expectations (e.g., DelVecchio et al. 2007; Kalwani and Yim 1992), increased consumer price sensitivity (e.g., Mela et al. 1997), and reduced brand loyalty (e.g., Dodson et al. 1978). Moreover, consumers may delay their purchases of such products in anticipation of future deals (Mela et al. 1998).

A number of studies investigate the short-term effects of discounts in the bundling context (e.g., Gilbride et al. 2008; Harris and Blair 2012; Janiszewski and Cunha 2004; Khan and Dhar 2010). However, little attention has been paid to the post-promotion effects of discounts on assessments of bundle components. Products offered free of charge with the purchase of another product represent a related research topic that will be discussed in greater detail below.

The aim of the present work is to investigate the post-promotion effects of bundle promotions. In particular, we discuss the effects of bundle promotions on postpromotion purchase probability and willingness to pay (WTP) for the bundled products. The main contribution of this research lies in investigating how these effects are moderated by the framing of the bundle promotion. Specifically, we consider the effects of assigning an equivalent discount to either the bundle price (joint bundling) or to a particular product, referred to as the "price leader", within the bundle (leader bundling). We differentiate between leader bundles with respect to whether the focal product-based upon which post-promotion effects are studied—or the other product in the bundle is presented as the price leader. We additionally investigate to what extent the effects spread over to non-promoted brands in the same product category as the brand shown in the bundle offers.

Choice-based conjoint analysis is utilized to identify the choice probability and WTP for a product previously offered within a joint or leader bundle.

The remainder of this article is structured as follows: First, a brief review of the relevant literature is given. Subsequently, the hypotheses are derived and the empirical study and results of the investigation are described. The last sections discuss the study's implications, its limitations and possible directions for future research. 


\section{Previous Literature}

Research on bundle discount framing focuses primarily on its short-term effects on consumer evaluations of the bundle offer. Such a discount can be framed in several ways. When joint bundling is used, the discount is assigned to the bundle as a whole ("buy products A and B together and pay only \$X"). The term "leader bundling" refers to a bundle in which one of the components is chosen as the price leader, which is offered at a discount when bought in conjunction with other bundled goods ("buy product B together with product A and pay only \$Y for product A").

Gilbride et al. (2008) report that joint bundling results in a higher percentage of bundle choices and a lower percentage of "no purchase" decisions than leader bundling.

Several researchers (see, e.g., Johnson et al. 1999; Janiszewski and Cunha 2004; Mazumdar and Jun 1993; Munger and Grewal 2001; Kaicker et al. 1995; Khan and Dhar 2010; Kwon and Jang 2011; Yadav 1994) have examined other bundle frames, which are not as common as joint- or leader bundling and are not considered in our study. While the results of these studies are somewhat contradictory, the conclusion to be drawn from them is that the framing of economically equivalent bundle discounts has a substantial influence on consumers' evaluations of bundle offers.

While the literature on the post-promotion effects of bundle discount framing is sparse, some researchers have investigated the impact of offering a product free of charge (free good) along with the purchase of another product on the WTP for the free good once the promotion is retracted. This stream of research provides interesting implications for our purposes because a freebie might be seen as a $100 \%$ price reduction on one component in the bundle (Janiszewski and Cunha 2004) and is therefore also discussed here.

Sheng et al. (2007) investigate the effect of a price discount offered for a product within a bundle on the evaluation of this product when it is later sold alone. They find that the perceived quality of this product decreases and that its regular price is subsequently judged to be more expensive. The higher the previous discount was, the more pronounced this effect is. Raghubir (2004) finds that consumers' WTP decreases for a product previously offered as a free good together with another (main) product. Palmeira and Srivastava (2013) also investigate bundles consisting of a main and a supplementary product. The supplementary product was offered either for free or at a discounted price. The WTP for the supplementary product when offered as a stand-alone product once the bundle promotion expired was lower in the second case. Contrary to Sheng et al. (2007), Palmeira and Srivastava report that the devaluation effect is the result of anchoring effects, not the result of a low perceived product quality. In summary, the results of these studies reveal that bundle discounts can negatively influence the evaluation of the bundled products. Some studies also point out that the framing of bundle discounts can influence these negative effects and therefore are closely related to our main research question. Sheng (2006) compares the influence of joint and leader bundling on attitudes towards the bundle components and the bundle as a whole. The results indicate that leader bundling generates more negative attributions (e.g., the bundled products are of inferior quality) about both 
bundle components than joint bundling. Raghubir (2005) indicates that consumers' WTP for a product previously offered as a free gift in a bundle is lower than when it is offered in an economically equivalent joint bundle. Kamins et al. (2009) demonstrate that the devaluation effect carries over to the main product in a bundle when the supplementary product is presented as a free gift.

Regarding the question whether negative effects may also spread over to other, non-promoted brands in the same product category as the brand presented in the bundle offer, Raghubir (2004) shows that the "value-discounting effect" transfers to other brands from the same product category as the free gift.

Overall, given the ubiquity of price bundling, the literature on post-promotion effects is sparse. The only paper comparing the impact of joint and leader bundling on the evaluation of bundled products (Sheng 2006) focuses on attributions but does not take into account other potential consequences of price bundling. Papers addressing the impact of freebies also investigate WTP with most authors (Raghubir 2004, 2005; Palmeira and Srivastava 2013) using open-ended questions to measure WTP. Direct questions assessing WTP have often been criticized (see, e.g., Breidert et al. 2006 for an overview of potential problems). Our use of choice-based conjoint (CBC) analysis allows an indirect measurement of WTP, avoiding the problems associated with direct surveys.

\section{Hypotheses}

As shown above, there is evidence that the framing of a bundle offer can influence evaluations. Several studies also indicate that price reductions for separately offered products can induce negative long-term effects. Here, the main focus is to investigate the post-promotion effects of differently framed discounts within a price bundle (under leader or joint bundling) on the purchase probability and WTP for a bundle component.

Table 1 provides an overview of the prices presented in different bundle offers.

We introduce the products and prices used in our empirical application here to make the presentation more vivid and concrete. The bundles used in our survey consist of a specific brand (hereafter referred to as the "focal brand") from the computer mouse product category (the "focal product category") and a keyboard as the other product. Each of the products was presented at either a regular price of $€ 20.99$ or at a $€ 7$ discount, resulting in a reduced price of $€ 13.99$.

While the regular, undiscounted price of a bundle would be $€ 41.98$ (i.e., the sum of the regular prices of the bundled products), the bundle was always offered for $€ 34.98$. The discount of $€ 7$ was displayed with one of the products when leader bundling was used and with the bundle when the joint bundle was presented.

A stand-alone product offered at the regular price (first line) is utilized as a control condition in the empirical section of this paper. In addition, a stand-alone product offered at a discount of $€ 7$ (last line) serves as a further standard of comparison.

As several studies indicate, price promotions have the potential to decrease reference prices (see, e.g., Blattberg et al. 1995; DelVecchio et al. 2007; Diamond and Campbell 1989; Kalwani and Yim 1992). Moreover, attribution theory suggests 
Table 1 Potential anchoring effects of different offers

\begin{tabular}{|c|c|c|c|c|}
\hline \multirow{2}{*}{$\begin{array}{l}\text { Focal product offered in } \\
\text { an advertisement: }\end{array}$} & \multicolumn{3}{|c|}{ Advertised price (anchor) } & \multirow{2}{*}{$\begin{array}{l}\text { Potential anchoring effect on focal } \\
\text { brand (mouse) }\end{array}$} \\
\hline & $\begin{array}{l}\text { Focal } \\
\text { brand } \\
\text { (mouse) }\end{array}$ & $\begin{array}{l}\text { Other } \\
\text { product } \\
\text { (keyboard) }\end{array}$ & $\begin{array}{l}\text { Bundle } \\
\text { (mouse }+ \\
\text { keyboard) }\end{array}$ & \\
\hline $\begin{array}{l}\text { Focal brand offered as } \\
\text { stand-alone product for } \\
\text { regular price }\end{array}$ & $\begin{array}{l}\text { Regular } \\
€ 20.99\end{array}$ & \multicolumn{2}{|c|}{ No price available } & No effect \\
\hline Joint bundle & $\begin{array}{l}\text { Regular } \\
€ 20.99\end{array}$ & $\begin{array}{l}\text { Regular } \\
€ 20.99\end{array}$ & $\begin{array}{l}\text { Reduced } \\
€ 34.98\end{array}$ & $\begin{array}{l}\text { Indirect }{ }^{\mathrm{a}} \text { effect of reduced bundle } \\
\text { price }\end{array}$ \\
\hline $\begin{array}{l}\text { Leader bundle; focal } \\
\text { brand is price leader }\end{array}$ & $\begin{array}{l}\text { Reduced } \\
€ 13.99\end{array}$ & $\begin{array}{l}\text { Regular } \\
€ 20.99\end{array}$ & $\begin{array}{l}\text { Reduced } \\
€ 34.98\end{array}$ & $\begin{array}{l}\text { Direct effect of reduced price and } \\
\text { indirect effect of reduced bundle } \\
\text { price }\end{array}$ \\
\hline $\begin{array}{l}\text { Leader bundle; other } \\
\text { product is price leader }\end{array}$ & $\begin{array}{l}\text { Regular } \\
€ 20.99\end{array}$ & $\begin{array}{l}\text { Reduced } \\
€ 13.99\end{array}$ & $\begin{array}{l}\text { Reduced } \\
€ 34.98\end{array}$ & $\begin{array}{l}\text { Indirect effect of reduced prices } \\
\text { of the other product and reduced } \\
\text { bundle price }\end{array}$ \\
\hline $\begin{array}{l}\text { Focal brand offered as } \\
\text { stand-alone product for } \\
\text { reduced price }\end{array}$ & $\begin{array}{l}\text { Reduced } \\
€ 13.99\end{array}$ & \multicolumn{2}{|c|}{ No price available } & Direct effect of reduced price \\
\hline
\end{tabular}

aThe term "direct effect" means that the price discount is shown with the price of the focal product, while an indirect effect may occur if the focal product is presented with its regular price and only discounted prices for the other bundle component or the bundle as a whole provide price cues with reduced prices. The term "indirect effect" does not refer to mediation here.

Reduced price quotations are presented in italic

that a discount can influence consumers' evaluations of the discounted product (see, e.g., Lichtenstein and Bearden 1986; Lichtenstein et al. 1989). Purchase likelihood might decrease if consumers assume an inferior product quality as the reason for a price promotion. Gedenk (2002) states that although it is unlikely that negative attributions of a price promotion might decrease consumers' purchase likelihood in the short term, it might do so in the long term. Once the promotion is retracted, the incentive for the purchase (the lower price) is no longer given. However, the negative attributions might persist.

As a consequence of a lower reference price and a lower perceived product quality, consumers' purchase probability is also expected to decrease. Just like a promotion for a stand-alone product, a bundle offer presenting the focal brand as the price leader presents this particular brand with a reduced price. We therefore hypothesize that

H1 Purchase probability for the focal brand decreases if it was previously presented as the price leader in a leader bundle.

Research on anchoring effects further reveals that the observed prices of a product can affect not only its reference price but also the reference prices of other products within the same product category (e.g., Adaval and Wyer 2011; Krishna et al. 2006; Urbany et al. 1988) or even reference prices of products in unrelated product categories (e.g., Adaval and Wyer 2011; Nunes and Boatwright 2004). When people encounter higher prices for related or unrelated products in their purchase environ- 
ment, they are willing to pay more for the product in question than in a purchase environment with lower prices. In a bundle, the price of the other (non-focal) product and the bundle price offer additional price cues. We therefore hypothesize that the purchase probability for a product decreases if the product has been offered as part of a joint bundle or in a leader bundle where another product is the price leader.

H2 Purchase probability for the focal brand decreases if this brand was previously presented

a) as part of a joint bundle or

b) within a leader bundle presenting a product from a different product category as the price leader.

The leader bundle with the focal brand as the leader is the only bundle offer in which the focal brand is shown with a reduced price, potentially causing more negative product associations and a greater decrease in the reference price. The effect of the reduced price of the focal brand is therefore expected to be more pronounced than the effects induced by other price cues as considered in $\mathrm{H} 2$.

H3 The decline in purchase probability is more pronounced when the focal brand was the price leader in a leader bundle relative to a bundle presenting the focal brand

a) as part of a joint bundle or

b) within a leader bundle presenting a product from a different product category as the price leader.

A product is presented only with its regular price if it is used either in a joint bundle or in a leader bundle in which the other product is the price leader. It is therefore not fully clear which condition will exhibit a stronger impact of price bundling on the evaluation of this product. So instead of a hypothesis we formulate a research question for the post-promotion effects of these bundles.

RQ Are post-promotion effects more pronounced if the focal brand was part of a joint bundle or the undiscounted product in a leader bundle where a product from a different category was the price leader?

This research question as well as Hypotheses $\mathrm{H} 1$ to $\mathrm{H} 3$ refer to the particular focal brand of the focal product category that was presented in the bundle offers. As described in Sect. 2 and documented by Raghubir (2004) for the case of free products, post-promotion effects might transfer to other brands within the product category. In our empirical study, we will also observe effects for two other brands, not presented in the bundle offers, in the focal product category. We expect the following for these brands:

H4 While presenting only the focal brand, the bundle offers also affect other brands, not displayed in the advertisements, in the same product category. 


\section{Empirical Study}

\subsection{Questionnaire}

As mentioned above, we used computer mice as the focal product category and keyboards as the other product in differently framed bundles (see Table 1). Brand A from the focal product category was the focal brand used in the advertisements, while brand $\mathrm{B}$ and brand $\mathrm{C}$ were other brands from the focal product category. ${ }^{1}$ Fig. 1 depicts the survey process.

In the questionnaire, each respondent was first exposed to one of five different advertisements ${ }^{2}$.

- Ad 1: Control group: Offer of a wireless computer mouse of focal brand A at the regular price of $€ 20.99$. A picture of the mouse was presented with the description": "Brand A Wireless computer mouse; Resolution: 2000dpi". The regular price of $€ 20.99$ was presented in a circle next to the picture along with a text above the picture stating "Brand A Mouse".

- Ad 5: Individual product reduced: The same mouse as in the control group was offered at a $€ 7$ price discount. The mouse was presented in exactly the same way as in Ad 1, but here the price in the circle was replaced by " $€ 13.99$ instead of $€ 20.99$ ". The text above the mouse was replaced by "Brand A mouse $33 \%$ off".

In each of the remaining advertisements, a bundle consisting of the same mouse as in Ad 1 and a keyboard was presented. The keyboard was described as "Brand D; human engineered keyboard; ultrathin design." The regular price was shown in a circle next to the picture as $€ 20.99$ for each of these products. The offers were economically equivalent, differing only in how the $€ 7$ discount was displayed.

- Ad 2 (Joint bundle): The savings were attributed to the bundle purchase with the circles close to the products presenting only the regular product prices. Below the pictures and descriptions of the products the text "Buy together and save: $€ 34.98$ instead of $€ 41.98$ " was displayed. The bottom of the advertisement repeated the bundle price: "Together for only $€ 34.98$ ".

- Ad 3 (Leader bundle; mouse is leader): The savings were attributed to the mouse. In the circle next to the picture of the mouse the price was replaced by " $€ 13.99$ instead of €20.99". The text below the pictures and descriptions of the products was replaced by "Buy together and save: Brand A computer mouse 33\% off. €13.99 instead of $€ 20.99 "$. The bundle price $€ 34.98$ was also presented at the bottom using the same wording as in the joint bundle offer.

- Ad 4 (Leader bundle; keyboard is leader): Equal to Ad 3, but with the savings attributed to the keyboard.

\footnotetext{
1 Real brand names, i.e. Ednet (brand A), Ultron and Revoltec (brand B and C) were used in the study. These brands were offering computer mice in the price range used in our study at the time the experiment was conducted.

2 Fig. 2 in the Appendix provides an example of a bundle offer.

3 The original advertisements were in German.
} 


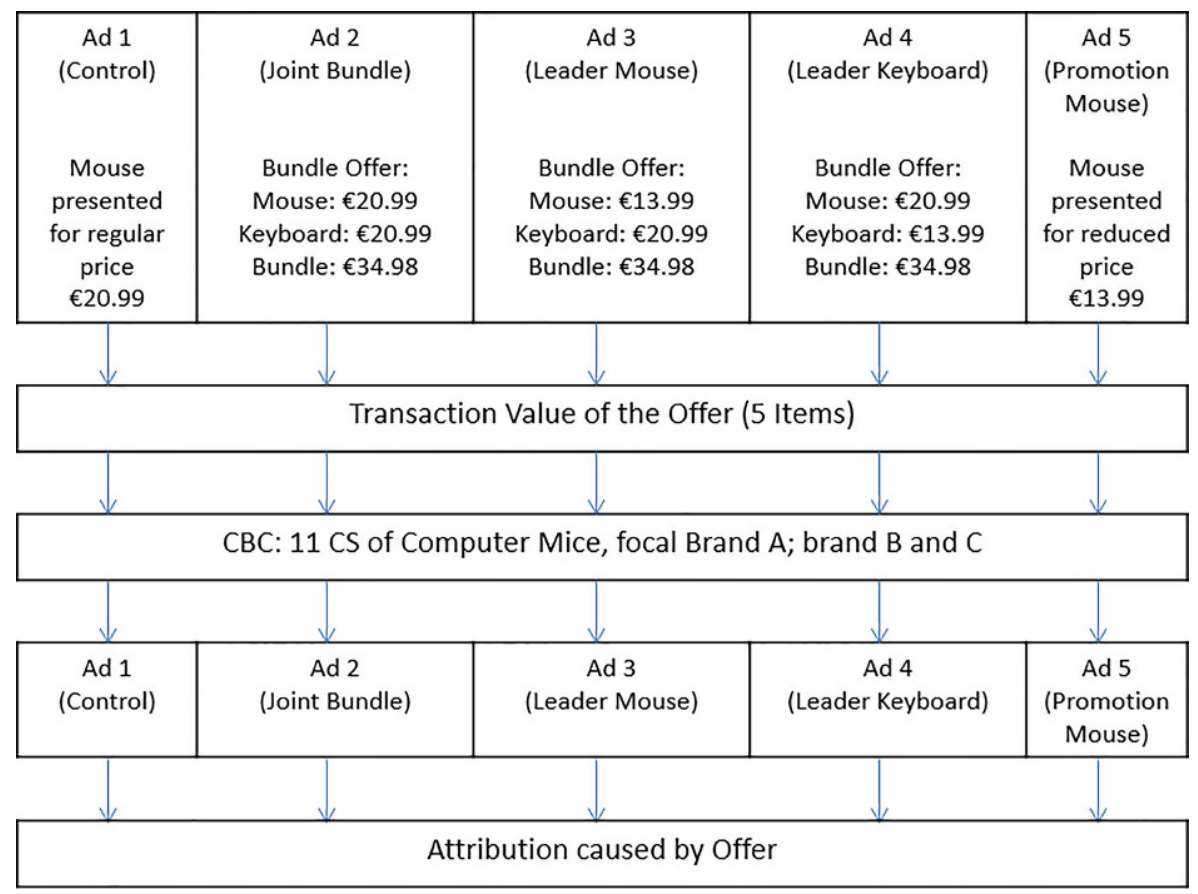

Fig. 1 Survey process

Note that while the absolute price reductions were equivalent, the relative price reductions were equivalent only between the bundle offers, while the relative reduction in advertisement 5 was larger. However, because our main goal is to compare the effects of differently framed bundles, we chose to forego a deeper discussion of this aspect.

Next, respondents were asked to evaluate the attractiveness of the offer, rating five items on the transaction value (Grewal et al. 1998; Sheng et al. 2007; Yadav and Monroe 1993) ${ }^{4}$, which is described by Thaler (1985) as "the merits of the deal".

Thereafter, each respondent was asked to evaluate eleven choice sets. Nine of these choice sets were used for estimation of the part-worth values, while the two remaining choice sets served as holdout tasks for evaluating predictive validity. In each of these choice tasks, a respondent had to decide whether he/she would buy one of three different alternatives of a computer mouse or nothing at all. The alternatives varied with respect to price, additional buttons, resolution and brand (see Table 2).

Subsequent to the evaluation of the choice tasks, each respondent saw the same advertisement again, rating several items regarding the attributions evoked by the price reduction ${ }^{5}$.

\footnotetext{
4 See the Appendix for the specific items.

5 See the Appendix for the specific items.
} 
Table 2 Attributes and attribute levels

\begin{tabular}{lllll}
\hline & Attributes & & & \\
& Price in $€$ & Additional buttons & Resolution & Brand \\
\hline Attribute level & 15.99 & Yes & 1500 dpi & A $^{\mathrm{a}}$ \\
& 17.99 & No & $2000 \mathrm{dpi}$ & $\mathrm{B}$ \\
& 19.99 & & & $\mathrm{C}$ \\
& 21.99 & & & \\
\hline 23.99 & & & \\
\hline
\end{tabular}

${ }^{\mathrm{a}}$ Focal brand

\subsection{Conjoint Methodology}

Conjoint analysis has proven its ability to reveal preferences in a variety of domains, with the $\mathrm{CBC}$ design emerging as the predominant method (see, e.g., Haaijer et al. 2001).

The multinomial logit (MNL) model (McFadden 1974) was applied to estimate respondents' part-worth utilities. The conditional choice probability is given by

$$
P_{\mathrm{ijc}}=\frac{\exp \left(V_{i j}\right)}{\sum_{j^{\prime} \in c} \exp \left(V_{i j^{\prime}}\right)}
$$

where $P_{i j c}=$ probability that respondent $i$ chooses alternative $j$ from choice set $c$.

The deterministic utility $V$ for alternative $j$ is specified by

$$
V_{i j}=\sum_{l=1}^{L} \sum_{m=1}^{m_{l}} \beta_{i l m} \cdot x_{j l m}
$$

where $\beta_{\text {ilm }}$ : part-worth of attribute level $m$ from attribute $l$ for respondent $i$,

$$
x_{j l m}=\left\{\begin{array}{l}
1, \text { if alternative } j \text { holds the attribute level } m \text { of attribute } l \\
0, \text { otherwise }
\end{array}\right.
$$

Each choice set in our empirical study consisted of three alternatives and a nopurchase option. The utility of the no-purchase option was normalized to 0 .

Several studies have shown that models allowing for heterogeneity perform better in terms of fit and predictive validity (see, e.g., Lenk et al. 1996; Rossi et al. 2009) than models assuming homogeneous preferences. This is why we applied a hierarchical Bayesian approach (HB) to estimate the vector of part-worths $\beta_{i}$ of the $\mathrm{CBC}$ model, under the assumption of normally distributed part-worths:

$$
\beta_{i} \sim N(\bar{\beta}, \Omega)
$$


Equation 2 is expanded to consider the influence of the previously seen advertisement:

$$
V_{i j}=\sum_{l=1}^{L} \sum_{m=1}^{m_{l}} \beta_{i l m} \cdot x_{j l m}+I_{j}^{A} \sum_{k=2}^{5} \delta_{k}^{A} \cdot D_{i k}+I_{j}^{B C} \sum_{k=2}^{5} \delta_{k}^{B C} \cdot D_{i k}
$$

Here, $D_{i k}$ is a dummy variable describing whether respondent $i$ had been exposed to advertisement $k(k=2 \ldots 5)$.

$$
D_{i k}=\left\{\begin{array}{l}
1, \text { if respondent } \mathrm{i} \text { has seen advertisement } \mathrm{k} \\
0, \text { otherwise }
\end{array}\right.
$$

$I_{j}^{A}$ is an indicator function taking value 1 if the advertised brand $\mathrm{A}$ is presented in alternative $j$.

$$
I_{j}^{A}=\left\{\begin{array}{l}
1, \text { if brand attribute in alternative } \mathrm{j} \text { is } \mathrm{A} \\
0, \text { otherwise }
\end{array}\right.
$$

In the same way, $I_{j}^{B C}$ describes whether one of the other brands $\mathrm{B}$ or $\mathrm{C}$ is presented in alternative $\mathrm{j}$.

The coefficient $\delta_{k}^{A}$ (respectively $\delta_{k}^{B C}$ ) captures the impact of exposure to advertisement $k$ on the utility of brand $\mathrm{A}$ (respectively $\mathrm{B}$ or $\mathrm{C}$ ) presented in alternative $\mathrm{j}$. We differentiate between the impacts of the advertisement on different brands to take into account that the impact on focal brand A may be different from the impact on the two other brands B or C. (e.g., $\delta_{2}^{A}$ describes the impact of exposure to a joint bundle in advertisement $2(k=2)$ on the utility for the advertised brand A, while $\delta_{2}^{B C}$ captures the impact of exposure to this bundle on the utility for brand B or C).

Note that the coefficients $\delta$ are not individually specific, such as $\beta_{i}$ in Eq. 3 . These coefficients can be interpreted as shifting the utility $V_{i j}$ by an amount of $\delta_{k}^{\mathrm{A}}$ $\left(\delta_{k}^{B C}\right)$ for all respondents exposed to advertisement $k$. If, for example, exposure to advertisement 2 presenting a joint bundle lowers the utility for brand A, the coefficient $\delta_{2}^{A}$ will have a negative sign.

The maximum WTP was calculated from the model in Eq. 4. Consumer $i$ will buy product $j$ as long as product utility is larger than or equal to the utility of not choosing the product, i.e.,

$$
V_{i j}=V_{i j \mid \sim p}+v_{i}(p) \geq 0 \text {. }
$$

$V_{i j \mid \sim p}$ represents the utility of alternative $j$ excluding price $p$, and $v_{i}(p)$ represents the utility of price. Note that $v_{i}(p)$ is expected to have a negative sign and therefore is added to $V_{i j \mid \sim p}$. An individual's maximum WTP for a certain product $j$ equals the maximum price for which the condition in Eq. 7 is satisfied.

When applying conjoint analysis to estimate WTP, researchers have frequently assumed a linear price-utility function. Under this assumption, WTP can be easily calculated by dividing $V_{i j \sim p}$ by the price coefficient. Sonnier et al. (2007) and Scarpa et al. (2008) propose another method, referred to as estimation in WTP space, that 
permits the direct estimation of WTP for product attributes. ${ }^{6}$ This approach is also based on the assumption of a linear price-utility relationship. In our empirical study, we found that a model estimating separate part-worths for every price attribute, and therefore not relying on the assumption of a linear relationship between price and utility, outperforms the model with a linear price-utility function and the model estimated in WTP space with respect to fit, calculated for the nine choice sets used for estimation, and predictive validity in two holdout choice sets. ${ }^{7}$ This indicates that the linearity assumption is not justified in our study, and we therefore stick to the approach of estimating part-worths for price attributes. We used a method described in detail by Miller et al. (2011) to calculate WTP with this approach, searching for the largest price attribute $\mathrm{p}_{\mathrm{m}}$ still satisfying condition (7). WTP was then calculated by linear interpolation between this price attribute and the next highest price attribute. ${ }^{8}$

\subsection{Data Collection}

Before starting the main study, two pretests were conducted with undergraduate students in a marketing class. The first pretest was utilized to determine the pricerange used in the study. The second pretest ensured that the products were, in general, appealing to the participants and that the questionnaire was feasible and coherent.

For the main study, participants who were at least 18 years old were recruited through a national online panel in the spring of 2015. A total of 317 individuals (of 397 who began the survey) completed the questionnaire and were used for estimation. The sample consisted of 147 (46.4\%) females and 170 males. The age in the sample ranged from 20 to 75 , with an average age of 45.47 years. The age group of $18-29$ years ( $9.8 \%$ compared to $17.0 \%$ of the overall German population) and the group of respondents older than 65 years $(7.6 \%$ compared to $24.6 \%)$ were underrepresented, whereas the groups between 30 and 49 years $(53.0 \%$ vs. $34.1 \%)$ and 50 to 64 years $(29.7 \%$ vs. $24.3 \%)$ were overrepresented. We still however assume that our sample represents the population better than student samples commonly used.

\section{Results}

\subsection{Transaction Value}

While the focus of this research is on the post-promotion effects of bundle framing, the short-term effects as measured by transaction value will briefly be summarized.

\footnotetext{
6 Schlereth and Skiera (2009) provide an extension of this method that allows the estimation of WTP Intervals.

7 Both fit and predictive validity were assessed based on log likelihood, hit rate and Brier score. All values were superior for the part-worth model.

${ }^{8}$ For further details about this method, we refer the reader to the paper by Miller et al. (2011), which also proposes a numerical example in the appendix.
} 
Table 3 Mean transaction values

\begin{tabular}{|c|c|c|c|c|}
\hline Ad 1 & Ad 2 & Ad 3 & Ad 4 & Ad 5 \\
\hline $\begin{array}{l}\text { Control group } \\
\text { (mouse for regu- } \\
\text { lar price) }\end{array}$ & $\begin{array}{l}\text { Joint } \\
\text { bundle }\end{array}$ & $\begin{array}{l}\text { Leader bundle } \\
\text { (mouse price } \\
\text { leader) }\end{array}$ & $\begin{array}{l}\text { Leader bundle } \\
\text { (keyboard price } \\
\text { leader) }\end{array}$ & $\begin{array}{l}\text { Individual product } \\
\text { (mouse) reduced }\end{array}$ \\
\hline$n=55$ & $n=61$ & $n=80$ & $n=55$ & $n=66$ \\
\hline 3.48 & 4.25 & 3.76 & 3.87 & 4.22 \\
\hline
\end{tabular}

Cronbach's $\alpha$ for the five items representing the transaction value for the different offers shown in the advertisement at the beginning of the questionnaire is 0.925 . According to Nunnally (1978), values of 0.7 and higher are acceptable. The mean transaction value in the particular group is shown in Table 3.

An analysis of variance reveals a significant difference in the mean transaction values between the groups ( $p$-value 0.043). It is not surprising that, according to a t-test, the offer of a mouse for the reduced price of $€ 13.99$ seemed significantly more attractive than the offer of the same mouse for the regular price of $€ 20.99$ ( $p$ value 0.015). In line with the findings by Gilbride et al. (2008) and Sheng (2006), the joint bundle condition was evaluated as more attractive than the leader bundle conditions, but only the difference between the joint and leader bundles using the mouse as the price leader was weakly significant $(p$-value $=0.073)$. The joint bundle also achieved a significantly higher transaction value than the offer at the regular price $(p$-value $=0.006)$, while neither the differences between the leader bundles and the regular price offer nor the differences between the leader bundles and the advertisement with the reduced price for the mouse were significant.

\subsection{Choice Frequencies}

Table 4 displays the post-promotion frequencies of choices of the three brands from the focal product category and the "no-purchase" option as observed in the conjoint experiment. These results are mainly descriptive, providing solely modelfree evidence while strong tests of the hypotheses are provided in Sect. 5.3.

A chi-squared test revealed a significant correlation $(p=0.031)$ between choice probabilities and the previously seen advertisement. Using bivariate t-tests, we found no significant difference in the choice probabilities for focal brand $\mathrm{A}$ and therefore no concrete indication of a direct effect of the advertisements on this brand's purchase probability.

A significant reduction in choice probability as compared to the control condition was observed for brand $\mathrm{C}$ when respondents were exposed to a joint bundle (Ad 2). Exposure to a leader bundle with the focal product (mouse) as the price leader (Ad 3) resulted in a significantly smaller purchase probability for brand B when compared to the other bundle offers (Ad 2 and Ad 4). These results may be interpreted as a partial support for Hypothesis H4, although it appears surprising that declining choice probabilities did not occur for focal brand A but did occur for the other brands B and C. We will discuss this observation in Sect. 6 together with the results for utilities and WTP. 
Table 4 Observed frequencies of choice in \%

\begin{tabular}{|c|c|c|c|c|}
\hline & A (focal brand) & B & $\mathrm{C}$ & No-purchase \\
\hline Ad 1: Control $(n=55)$ & 27.77 & $23.97-$ & $23.80(2)^{* * *}$ & $\begin{aligned} 24.46 & (2)^{* *} \\
& (3)^{* *} \\
& (5)^{* *}\end{aligned}$ \\
\hline Ad 2: Joint Bundle $(n=66)$ & 25.76 & $25.62(3)^{* *}$ & $18.73(1)^{* *}$ & $\begin{array}{c}29.89(1)^{* *} \\
(4)^{*}\end{array}$ \\
\hline $\begin{array}{l}\text { Ad 3: Leader Mouse } \\
(n=61)\end{array}$ & 28.32 & $\begin{aligned} 20.57 & (2)^{* *} \\
& (4)^{* * *}\end{aligned}$ & $20.27-$ & $\begin{array}{r}30.85(1)^{* *} \\
(4)^{* *}\end{array}$ \\
\hline $\begin{array}{l}\text { Ad 4: Leader Keyboard } \\
(n=80)\end{array}$ & 25.57 & $27.61(3)^{* * *}$ & $20.80-$ & $\begin{aligned} 26.02 & (2)^{*} \\
& (3)^{* *} \\
& (5)^{*}\end{aligned}$ \\
\hline $\begin{array}{l}\text { Ad 5: Promotion Mouse } \\
(n=55)\end{array}$ & 24.63 & $24.46-$ & $20.50-$ & $\begin{aligned} 30.41(1)^{* *} \\
(4)^{*}\end{aligned}$ \\
\hline
\end{tabular}

$(\mathrm{k})^{*}$ : different from choice frequency in Group Ad k; $p$-value $<0.10$

$(\mathrm{k})^{* *}$ : different from choice frequency in Group Ad $\mathrm{k} ; p$-value $<0.05$

$(\mathrm{k})^{* * *}$ : different from choice frequency in Group Ad k; $p$-value $<0.01$

Significant differences between groups were observed for the choice probabilities of the no-purchase option. The fact that respondents who saw a promotion for the mouse as a stand-alone product at a reduced price (Ad 5) chose the no-purchase option significantly more often than people who saw the same product at the regular price confirms findings from studies reporting negative post promotion effects not only for the promoted brand but for the product category as well (Raghubir 2004; Adaval and Wyer 2011; Krishna et al. 2006; Urbany et al. 1988). Respondents who saw the mouse as part of a joint bundle (Ad 2) or as the leader in a leader bundle (Ad 3) exhibited a relative number of choices of the no-purchase option that was significantly lower compared to the control group, and similar to that of the group that saw Ad 5.

In summary, we cannot report direct model-free evidence for the hypotheses with respect to choice frequencies. However, the fact that respondents who saw the bundle offers in Ads 2 or 3 were significantly more likely not to buy within the focal product category provides some indication that these bundle offers have negative effects.

\subsection{Results of the Conjoint Analysis}

The HB estimation was performed with ten different starting values for the Markov chain. We present the results from the chain providing the best fit below, as measured by log-likelihood. A burn-in period of 100,000 draws was utilized. Every tenth draw of the subsequent 100,000 iterations was used to estimate the posterior distribution of the coefficients.

We used the mean of these 10,000 draws as an estimator of the coefficient and the relative frequency of positive or negative draws to assess the probability that the coefficient had the corresponding sign (e.g., in Table 5 below, the coefficient of 0.993 for brand A indicates that in $99.3 \%$ of the draws, the sign was positive and therefore the coefficient is highly likely to have a positive sign). To compare different 
coefficients, we calculated the relative frequency of draws where one coefficient was larger than the other.

Note that in Bayesian statistics, probabilities are reported to make statements about coefficients, while in frequentist statistics, $p$-values are used to assess significance. To improve readability, we will use the term "significance" as a colloquial term in the following although it does not describe significance in the same way as in frequentist statistics.

A potential problem arises from the fact that several respondents chose the nopurchase option in every $(10.7 \%)$ or no $(41.6 \%)$ choice set. Gensler et al. (2012) argue that this kind of extreme choice behavior has the potential to lead to invalid estimates of consumer WTP. However, excluding respondents exhibiting this kind of behavior is not reasonable in our study, because it is dependent on the advertisement the respondent had been exposed to (e.g. the number of respondents always choosing the no-purchase option significantly increased for respondents previously exposed to Ad 2, 3 or 5 ).

Table 5 shows the estimated coefficients of the $\mathrm{CBC}$ with the utility function in Eq. 4.

We summarize the relevant findings in Table 6 to illustrate whether the results support the hypotheses formulated in Sect. 3. In the first line of each cell in the second column, we describe the necessary values of the coefficients $\delta_{k}^{A}$ to support the hypothesis (e.g., if $\delta_{3}^{A}$ is negative, Hypothesis H1 is supported). In each cell's second line, the estimated probability that the condition is met is presented, and the conclusion is reported in the third line (i.e., weak support for the hypothesis if the probability is larger than $90 \%$ and support if the probability is larger than $95 \%$ ). The last column shows the results for the other brands $\mathrm{B}$ and $\mathrm{C}$ and will be used below to assess whether Hypothesis H4 is supported.

It should be noted that comparing the evidence presented here to the model-free evidence presented in Sect. 5.2 is not straightforward. For example, the significantly negative coefficients for $\delta_{2}^{A}$ and $\delta_{2}^{B C}$ generate a decreased utility for all brands if a respondent has seen Ad 2. Therefore, the probability of choosing either brand is decreased and the choice probability of the no-choice option is increased. This is mirrored by the significantly higher choice-frequency of the no purchase option in group 2 as compared to the control group. However, depending on the bundle offers' concrete effects on different brands significant differences in choice frequencies for a certain brand might also be observed.

When looking at the results for the focal brand A, we find (weak) support for hypotheses $\mathrm{H} 1$ and $\mathrm{H} 2$ a proposing that the brand's assessment is negatively affected if this brand is presented as the price leader in a leader bundle or as part of a joint bundle. Hypothesis $\mathrm{H} 3 \mathrm{a}$, proposing that the effect is larger in the first case, is not supported.

Using the focal brand within a leader bundle containing a product from another category as the price leader (Ad 4) has only a marginal effect on the brand's purchase probability. Therefore, $\mathrm{H} 2 \mathrm{~b}$ is not supported. We also find no support for Hypothesis $\mathrm{H} 3 \mathrm{~b}$, as there is no significant difference between this kind of price bundle and a bundle presenting the focal brand as price leader (Ad 3). With respect to the research question formulated in Sect. 3, we find a weak indication of a larger 
Table 5 Coefficients estimated in the HB-MNL model

\begin{tabular}{lcl}
\hline & Coefficient & $\begin{array}{l}\text { Relative number of draws with identical } \\
\text { sign as coefficient }\end{array}$ \\
\hline Brand A & 1.727 & 0.993 \\
Brand B & 1.361 & 0.966 \\
Brand C & 1.442 & 0.969 \\
Price $€ 17.99$ & -0.965 & 0.999 \\
Price $€ 19.99$ & -2.091 & 1.000 \\
Price $€ 21.99$ & -4.347 & 1.000 \\
Price $€ 23.99$ & -6.027 & 1.000 \\
Additional buttons & 2.481 & 1.000 \\
High resolution & 2.230 & 1.000 \\
Influence of previously seen advertisement on brand A: & \\
Joint bundle $\left(\delta_{2}^{A}\right)$ & -1.952 & 0.959 \\
Mouse is price leader $\left(\delta_{3}^{A}\right)$ & -1.599 & 0.934 \\
Keyboard is price leader $\left(\delta_{4}^{A}\right)$ & -0.580 & 0.702 \\
Promotion mouse $\left(\delta_{5}^{A}\right)$ & -1.245 & 0.919 \\
Influence of previously seen advertisement on brand B and C: \\
Joint bundle $\left(\delta_{2}^{B C}\right)$ & -1.683 & 0.936 \\
Mouse is price leader $\left(\delta_{3}^{B C}\right)$ & -1.616 & 0.938 \\
Keyboard is price leader $\left(\delta_{4}^{B C}\right)$ & -0.345 & 0.615 \\
Promotion mouse $\left(\delta_{5}^{B C}\right)$ & -1.367 & 0.921 \\
\hline
\end{tabular}

negative influence of a joint bundle (Ad 2) on post-promotion purchase probability as compared to a leader bundle (Ad 4) where a product from another category is the price leader.

According to Hypothesis H4, we expected that the observed decline in purchase probability would transfer to other brands in the focal product category. We could not find considerable differences when comparing the evidence reported in the last column for brand $\mathrm{B}$ and $\mathrm{C}$ with the respective results in the second column for brand A. With respect to a potentially negative impact of joint bundling, as proposed in Hypothesis $\mathrm{H} 2 \mathrm{a}$ for the focal brand $\mathrm{A}$, we find support for this brand but only weak support for a transfer of this effect to the other brands B and C. However, the difference in the probabilities for a negative effect is relatively small. In summary, Hypothesis H4 is essentially supported.

In order to further illustrate the concrete effects of price bundling we calculated WTP for each of the five groups. The mean $\mathrm{WTP}_{\mathrm{k}}$ values for respondents having been exposed to one of the advertisements $\mathrm{k}=1 \ldots 5$ are reported in Table 7 . WTP was calculated for computer mice with high resolution because this kind of mouse was presented in the advertisements. Slight differences between the significance values reported in Table 7 as compared to the evidence reported in Table 6 can be attributed to the calculation of the WTP (see Sect. 4.2), which utilizes individualspecific part-worth values for the attributes while the coefficients $\delta$ model a shift in the population mean of the utilities of all respondents who saw the respective advertisement. 
Table 6 Support for hypotheses

\begin{tabular}{|c|c|c|}
\hline Hypotheses & Focal Brand A & $\begin{array}{l}\text { Brand B and C } \\
\text { (refers to H4) }\end{array}$ \\
\hline $\begin{array}{l}\text { H1: Purchase probability for the [...] } \\
\text { brand decreases if the focal brand was } \\
\text { previously presented as the price leader } \\
\text { in a leader bundle }\end{array}$ & $\begin{array}{l}\delta_{3}^{A}<0 \\
\text { probability } 0.934 \\
\text { weak support }\end{array}$ & $\begin{array}{l}\delta_{3}^{B C}<0 \\
\text { probability } 0.938 \\
\text { weak support }\end{array}$ \\
\hline \multicolumn{3}{|l|}{$\begin{array}{l}\mathrm{H} 2 \text { : Purchase probability for the }[\ldots] \\
\text { brand decreases if the focal brand was } \\
\text { previously presented }\end{array}$} \\
\hline a: as part of a joint bundle & $\begin{array}{l}\delta_{2}^{A}<0 \\
\text { probability } 0.959 \\
\text { support }\end{array}$ & $\begin{array}{l}\delta_{2}^{B C}<0 \\
\text { probability } 0.936 \\
\text { weak support }\end{array}$ \\
\hline $\begin{array}{l}\text { b: within a leader bundle presenting } \\
\text { a product from a different product } \\
\text { category as the price leader }\end{array}$ & $\begin{array}{l}\delta_{4}^{A}<0 \\
\text { probability } 0.702 \\
\text { no support }\end{array}$ & $\begin{array}{l}\delta_{4}^{B C}<0 \\
\text { probability } 0.615 \\
\text { no support }\end{array}$ \\
\hline \multicolumn{3}{|l|}{$\begin{array}{l}\text { H3:The decline in purchase probability } \\
\text { is more pronounced when the focal } \\
\text { brand was the price leader in a leader } \\
\text { bundle relative to a bundle presenting } \\
\text { the focal brand }\end{array}$} \\
\hline a: as part of a joint bundle & $\begin{array}{l}\left|\delta_{3}^{A}\right|>\left|\delta_{2}^{A}\right| \\
\text { probability } 0.392 \\
\text { no support }\end{array}$ & $\begin{array}{l}\left|\delta_{3}^{B C}\right|>\left|\delta_{2}^{B C}\right| \\
\text { probability } 0.490 \\
\text { no support }\end{array}$ \\
\hline $\begin{array}{l}\text { b: within a leader bundle presenting } \\
\text { a product from a different product } \\
\text { category as the price leader }\end{array}$ & $\begin{array}{l}\left|\delta_{3}^{A}\right|>\left|\delta_{4}^{A}\right| \\
\text { probability } 0.824 \\
\text { no support }\end{array}$ & $\begin{array}{l}\left|\delta_{3}^{B C}\right|>\left|\delta_{4}^{B C}\right| \\
\text { probability } 0.883 \\
\text { no support }\end{array}$ \\
\hline $\begin{array}{l}\text { RQ: Are post-promotion effects more } \\
\text { pronounced if the focal brand was part } \\
\text { of a joint bundle or the undiscounted } \\
\text { product in a leader bundle where } \\
\text { a product from a different category } \\
\text { was the price leader? }\end{array}$ & $\begin{array}{l}\left|\delta_{2}^{A}\right|>\left|\delta_{4}^{A}\right| \\
\text { probability } 0.902 \\
\text { weak evidence for more } \\
\text { pronounced effects when } \\
\text { part of joint bundle }\end{array}$ & $\begin{array}{l}\left|\delta_{2}^{B C}\right|>\left|\delta_{4}^{B C}\right| \\
\text { probability } 0.905 \\
\text { weak evidence for more } \\
\text { pronounced effects when } \\
\text { part of joint bundle }\end{array}$ \\
\hline
\end{tabular}

Respondents in the group exposed to Ad 4 differed only marginally and insignificantly from the control group in their WTP for all brands. This result mirrors the finding of no significant effect on purchase probability as measured by $\delta_{4}$. Being a bundle component in a leader bundle thus has no negative consequence for products of the category which was not featured as the price leader in the bundle.

In regard to the joint bundle, a weakly significant reduction in WTP of $€ 0.72$ was observed for focal brand $\mathrm{A}$, whereas the impact was insignificant for the other brands. In contrast to the results above regarding the coefficients $\delta_{2}$, there is a less clear indication of an impact of this bundle type.

A reduction in WTP of more than one euro was observed when a product of the focal category "mouse" was used as the price leader. This difference in WTP was significant, whereas the difference in purchase-probability (i.e. $\delta_{3}$ in Table 6) was only weakly significant. While analysis of the coefficients $\delta$ has shown no indication of a significant difference between different bundle offers, WTP was lower for nonfocal brands $\mathrm{B}$ and $\mathrm{C}$ when this bundle was used compared to other bundle types. 
Table 7 WTP for computer mouse

\begin{tabular}{|c|c|c|c|}
\hline & Brand A $\left(\mathrm{WTP}_{k}^{A}\right)$ & Brand $\mathrm{B}\left(\mathrm{WTP}_{k}^{B}\right)$ & Brand C $\left(\mathrm{WTP}_{k}^{C}\right)$ \\
\hline Ad 1: Control $(n=55)$ & $\begin{aligned} 21.34 & (2)^{*} \\
& (3)^{* *} \\
& (5)^{* *}\end{aligned}$ & $\begin{aligned} 20.97 & (3)^{* * *} \\
& (5)^{* * *}\end{aligned}$ & $\begin{aligned} 21.11 & (3)^{* * *} \\
& (5)^{* * *}\end{aligned}$ \\
\hline Ad 2: Joint Bundle $(n=66)$ & $20.62(1)^{*}$ & $\begin{aligned} 20.62 & (3)^{*} \\
& (5)^{* *}\end{aligned}$ & $20.61(5)^{* *}$ \\
\hline Ad 3: Leader Mouse $(n=61)$ & $\begin{array}{c}20.27(1)^{* *} \\
(4)^{*}\end{array}$ & $\begin{aligned} 19.65 & (1)^{* * *} \\
& (2)^{*} \\
& (4)^{* *}\end{aligned}$ & $\begin{array}{r}19.97(1)^{* * *} \\
(4)^{* *}\end{array}$ \\
\hline Ad 4: Leader Keyboard $(n=80)$ & $\begin{aligned} 21.03 & (3)^{*} \\
& (5)^{* *}\end{aligned}$ & $\begin{aligned} 20.98 & (3)^{* * *} \\
& (5)^{* * *}\end{aligned}$ & $\begin{array}{r}20.99(3)^{* *} \\
(5)^{* * *}\end{array}$ \\
\hline Ad 5: Promotion Mouse $(n=55)$ & $\begin{array}{r}19.99(1)^{* * *} \\
(4)^{* *}\end{array}$ & $\begin{aligned} 18.97 & (1)^{* * *} \\
& (2)^{* *} \\
& (4)^{* * *}\end{aligned}$ & $\begin{aligned} 19.17 & (1)^{* * *} \\
& (2)^{* *} \\
& (4)^{* * *}\end{aligned}$ \\
\hline
\end{tabular}

$(\mathrm{k})^{*}$ : different from WTP in group Ad k with probability $>90 \%$

$(\mathrm{k})^{* *}$ : different from WTP in group Ad $\mathrm{k}$ with probability $>95 \%$

$(\mathrm{k})^{* * *}$ : different from WTP in group Ad k with probability $>99 \%$

While this paper focuses on the post promotion effects of differently framed price bundles, we also briefly compare the effects of the price bundles with the effects of a price promotion for the focal brand as a stand-alone product in advertisement 5 . Although $\left|\delta_{5}^{A}\right|$ is slightly lower on average (see Table 5) than $\left|\delta_{2}^{A}\right|$ and $\left|\delta_{3}^{A}\right|$, the corresponding relations could only be observed in considerably less than $90 \%$ of the draws and thus cannot be regarded as significant. This also applies to the comparison of the respective coefficients $\delta^{B C}$ for the other brands B and C. So the decline in purchase probability when one of the price bundles in advertisement 2 or 3 was presented is comparable to the effect of a price promotion for the focal brand as a stand-alone product.

With regard to WTP, the difference between a price promotion for focal brand $\mathrm{A}(\mathrm{Ad} 5)$ and the joint bundle (Ad 2) was less pronounced (the probability $\mathrm{WTP}_{5}^{A}<\mathrm{WTP}_{2}^{A}$ was $85.5 \%$ ) compared to brands $\mathrm{B}$ and $\mathrm{C}$ (the probability was greater than $95 \%$ for both brands). For all brands, the WTP after an advertisement for the mouse as a stand-alone product (Ad 5) was not significantly lower than when the mouse was used as the price leader in a leader bundle (Ad 3). In contrast, the WTP after respondents saw the promotion in advertisement 5 was lower with a probability of more than $95 \%$ for all brands compared to a leader bundle presenting a product from another category (Ad 4) as the price leader.

\subsection{Analysis of the Attribution Items}

Negative attributions of the product were assumed to be one possible explanation for a decrease in purchase probability and WTP following a price promotion. In most instances, person attributions (e.g., "the seller wants to attract new customers") are positively related to price-evaluation-dependent measures, whereas product attributions (e.g., "the product is of inferior quality") are negatively related. Circumstance attributions (e.g., "there has been an oversupply of this product") are not related to 
Table 8 Mean values of attribution items

\begin{tabular}{|c|c|c|c|c|c|c|}
\hline & $\begin{array}{l}\text { Control } \\
\text { group } \\
n=55\end{array}$ & $\begin{array}{l}\text { Joint } \\
\text { bun- } \\
\text { dle } \\
n=66\end{array}$ & $\begin{array}{l}\text { Leader bundle } \\
\text { (mouse price } \\
\text { leader) } \\
n=61\end{array}$ & $\begin{array}{l}\text { Leader bundle } \\
\text { (keyboard price } \\
\text { leader) } \\
n=80\end{array}$ & $\begin{array}{l}\text { Ind. product } \\
\text { (mouse) } \\
\text { reduced } \\
n=55\end{array}$ & $\begin{array}{l}p \text {-value } \\
\text { ANOVA }\end{array}$ \\
\hline $\begin{array}{l}1 \text { quality } \\
\text { of mouse is } \\
\text { inferior }\end{array}$ & 4.091 & 4.318 & 4.459 & 4.312 & 4.473 & 0.893 \\
\hline $\begin{array}{l}2 \text { quality of } \\
\text { keyboard is } \\
\text { inferior }\end{array}$ & NA & 4.439 & 4.607 & 5.125 & NA & 0.291 \\
\hline $\begin{array}{l}3 \text { stimu- } \\
\text { late sales of } \\
\text { mouse }\end{array}$ & 6.600 & 5.909 & $6.984(2 *)$ & $6.912(2 *)$ & $6.927(2)$ & 0.014 \\
\hline $\begin{array}{l}4 \text { mouse is } \\
\text { a remnant }\end{array}$ & 5.382 & 5.652 & $6.557(1 *)$ & 6.025 & 6.309 & 0.021 \\
\hline $\begin{array}{l}5 \text { attract new } \\
\text { customers }\end{array}$ & 6.455 & 7.136 & 7.279 & 6.900 & 6.927 & 0.15 \\
\hline $\begin{array}{l}6 \text { planned to } \\
\text { reduce price }\end{array}$ & 5.455 & 4.955 & $6.033(2)$ & 5.200 & 5.945 & 0.029 \\
\hline $\begin{array}{l}7 \text { stimulate } \\
\text { cross-sales }\end{array}$ & 6.273 & 7.121 & $7.246(1)$ & 6.975 & 6.945 & 0.062 \\
\hline $\begin{array}{l}8 \text { adaptation } \\
\text { to competitor } \\
\text { prices }\end{array}$ & 5.909 & 5.758 & 6.049 & 5.662 & 6.309 & 0.398 \\
\hline $\begin{array}{l}9 \text { no suffi- } \\
\text { cient demand } \\
\text { (mouse) }\end{array}$ & 5.255 & 5.561 & $6.623\left(1^{*}, 2^{*}\right)$ & $6.662\left(1^{*}, 2^{*}\right)$ & $6.473(1 *)$ & 0.000 \\
\hline $\begin{array}{l}10 \text { price was } \\
\text { excessive }\end{array}$ & 5.418 & 5.955 & $6.459(1)$ & 6.025 & 6.036 & 0.136 \\
\hline
\end{tabular}

$\left(1^{*}\right)$ Significantly larger $(p<0.05),(1)$ weakly significantly larger $(p<0.1)$ than the control group $(2 *)$ Significantly larger $(p<0.05),(2)$ weakly significantly larger $(p<0.1)$ than the joint bundle Significant $p$-values in the last column (ANOVA) are shown in italic

$N A$ Not available because the keyboard was not presented in these groups

these measures at all (Lichtenstein et al. 1989). The mean values for the particular attributions, measured on a seven-point Likert scale (1: not at all probable, 7: highly probable) in the last step of the survey process (see Fig. 1) can be seen in Table 8.

Respondents who saw advertisements with price reductions were slightly more likely than the control group to perceive that the advertised mouse (item 1) was of inferior quality. The highest values could be found in the groups where the price reduction was directly assigned to the focal brand (leader mouse and individual product price reduction). However, none of these differences were significant. Accordingly, respondents who saw an advertisement for a leader bundle where the keyboard was the price leader did not exhibit a significantly higher perception of the keyboard as being inferior to those who saw the other bundle conditions.

The attribution that the mouse is a remnant (item 4) was higher for respondents who saw advertisements with price reductions than for respondents in the control group. However, there was only a significant difference between the leader bundle 
condition in which the mouse was offered as the price leader and the control condition. Overall, this implies that we cannot find a clear indication that price promotions induce more negative product attributions than offering a product at its regular price.

We observed significant differences for the attribution that the sales of the mouse should be stimulated (item 3 ). This attribution could be observed least in the condition in which the mouse was offered in a joint bundle. The mean value for the attribution was significantly higher for the two leader conditions and the individual product price reduction condition. The answers to item 9 ("no sufficient demand for mouse") provided further support for these results. Here, significant differences could also be found between the control group and the two leader conditions, as well as between the control group and the condition in which the individual product was offered at a reduced price. Beyond this, there are only a few weakly significant results.

It becomes obvious that the respondents predominantly assumed that price reductions were implemented to promote sales and, to a much lesser extent, as a result of inferior quality. This conclusion is also consistent with the results of the CBC analysis. If the respondents assumed that the promoted product was of inferior quality, then the purchase probability and WTP of the promoted brand, but not those of the other brands, would have decreased. The fact that the purchase probability and WTP of the other brands also decreased indicates that an anchoring effect was present. Overall, it seems that anchoring effects are much better suited to explain the negative impact of promotions on product evaluation than negative attributions regarding brand quality.

\section{Discussion and Managerial Implications}

The literature demonstrates that various types of promotions and the framing of economically equivalent savings can influence sales in different ways. However, marketing managers must bear in mind the post-promotion consequences of these promotional activities.

While short-term effects were briefly observed, our main focus was on the particular post-promotion effects of offering a product within differently framed price bundles on its purchase probability and WTP once the bundle offer is retracted and the product is offered as a stand-alone product.

Overall, the results of this study point out that offering a product in combination with a price reduction has the potential to generate negative consumer assessments of it once the price reduction is retracted. This effect is comparably strong when the product is presented as the price leader within a leader bundle compared to an offering of the individual product with the same savings. In both of these offerings, the price reduction is directly associated with the product. Because price promotions induce only marginal negative attributions about product quality, reference price effects explain this observation.

Other brands in the same product category as the advertised brand also experience a deterioration in product evaluations. So reducing the price for one brand in a product category can also affect other brands from the same category. This 
outcome confirms the results proposed by Adaval and Wyer (2011), Krishna et al. (2006) and Urbany et al. (1988) and extends these results to offerings where the product is presented with a price reduction within a price bundle.

An unexpected result is that the negative post-promotion effects of price bundling for the other brands in the focal product category are sometimes even larger than that for focal brand A used in the advertisement. One possible explanation for this is that the focal brand's offering in a bundle also has positive advertising effects for this particular brand, which mitigates the negative reference price effect. Note, however, that in regard to WTP this stronger effect was observed for the promotion of the mouse as a stand-alone product and one of the bundle offers (i.e. the bundle using the focal product as price leader) but not for the other bundles. With regard to the choice frequencies in the choice sets actually used (see Table 4 in Sect. 5.2) a stronger effect was only observed for brand B when this bundle offer was used and for brand $\mathrm{C}$ when a joint bundle was presented, but not for the other bundles. The values of the parameters $\delta$, which were used to investigate model-based evidence for our hypotheses, did not indicate a stronger effect on the other brands' purchase probabilities.

In summary, while the results provide a clear indication that negative effects transfer to other brands in the focal category, the question of whether these effects might be even stronger than those for the actually advertised focal brand cannot be conclusively answered.

The purchase probability and WTP for a product are not significantly affected if this product is used in a bundle where a product from another category is the price leader. We therefore find no support for a relevant effect of reference prices on products from other categories as proposed by Adaval and Wyer (2011) or Nunes and Boatwright (2004).

Comparing our findings to the results reported in the literature on price bundling and free offers (see Sect. 2), we can confirm the existence of negative post-promotion effects of using a product within a price bundle. Our conclusion that these effects result from reference effects while no significant negative attributions about product quality occur confirms the findings of Palmeira and Srivastava (2013) but contrasts with the empirical results presented by Sheng (2006) and Sheng et al. (2007). The fact that in our study, the negative post-promotion effects carry over to the entire product category mirrors the finding by Raghubir (2004) in a free offer setting. Raghubir (2005) further reports that WTP for a product is lower if it was used as a free product before than in the case of an offer in which the product was offered together in a bundle in which the other product was offered for free. This finding is mirrored by our results concerning different leader bundles where we found negative effects of presenting the product as the price leader but no negative effects when a product from another category was presented as the leader. However, contrary to Raghubir's (2005) findings, a joint bundle has negative effects comparable to a leader bundle that presents the focal product as the leader.

Our results do not allow us to go so far as to provide general advice about the best framing of price bundles to retailers. Regarding the short-term effects, the highest transaction value can be achieved with joint bundling and an individual price reduction, with both offers appearing to damage the post-promotion evaluation of 
the product. However, when using a leader bundle, the evaluation of the price leader, but not the other product, is negatively affected. Therefore, when deciding how to frame a price reduction within a price bundle, managers should take the concrete circumstances and aims into account. If, for example, the primary goal is to avoid negative post-promotion effects for one of the products because the other product will be dropped from the product range after the promotion, then leader bundling with the latter product as the price leader might be the best option.

\section{Future Research Directions and Limitations}

The results of this study reveal that the framing of price reductions in the bundling context affects consumers' purchase probability and WTP for a product once it is sold as a stand-alone product. Other brands from the same product category as the product offered in a price bundle are also negatively affected. While several of the results are only weakly significant, we believe that the study still provides interesting implications, as discussed in Sect. 6.

As with every empirical study, this research has several limitations, some of which might serve as the starting point for future research.

Our results provided some indication that the negative effects of bundle promotions on other brands not presented in the advertisements might be even larger than the effects on the particular brand used in the advertisement. However, the results are ambiguous on this question, and the increased effect on other brands can be neither verified nor rejected. We leave this question to future research.

The purchase decisions used to measure WTP are only hypothetical choices. Respondents were not required to buy the product they chose. Therefore, their choices had no real consequences. Our research design also did not enable us to investigate the post-promotion effects on product evaluation and repurchase behaviour after the product was purchased and used. Self-perception theory represents a starting point for empirical studies investigating this kind of post-promotion effect. It would be interesting to see whether future research can replicate the results in real purchase decisions. In general, transactional data may be more suitable for uncovering postpromotion effects. However, considering the research questions in our study, transactional data on differently framed price bundles within the same product category and with equivalent price reductions would be necessary. Because it would probably be very difficult to find secondary data that meet this requirement, a field experiment would be suitable to obtain appropriate data.

Moreover, only one product group was studied. For the sake of generalizability, these findings should be verified for other product groups and the service sector. The number of bundle components could also play a role in this context. In our study, only bundles with two bundle components were examined. According to Krishna et al. (2002), consumers value the savings on bundles less as the number of bundle components increases.

The same regular price for both products in the bundle and only one price reduction amount were used for the price setting. Future research should investigate 
the effect of price discount framing on differently priced bundle components, and varying degrees of price reduction.

Acknowledgements We gratefully acknowledge the constructive comments and useful suggestions of two anonymous reviewers and the area editor.

Open Access This article is licensed under a Creative Commons Attribution 4.0 International License, which permits use, sharing, adaptation, distribution and reproduction in any medium or format, as long as you give appropriate credit to the original author(s) and the source, provide a link to the Creative Commons licence, and indicate if changes were made. The images or other third party material in this article are included in the article's Creative Commons licence, unless indicated otherwise in a credit line to the material. If material is not included in the article's Creative Commons licence and your intended use is not permitted by statutory regulation or exceeds the permitted use, you will need to obtain permission directly from the copyright holder. To view a copy of this licence, visit http://creativecommons.org/licenses/by/4. $0 /$.

Funding This research was funded by the German Research Foundation (Deutsche Forschungsgemeinschaft, BA 2902/2-1).

Funding Open Access funding provided by Projekt DEAL.

\section{Appendix}

\section{Survey Items}

\section{Transaction Value}

- If I bought the previously seen product (offer), the deal I would be getting is very good (Yadav and Monroe 1993).

- I would be satisfied if I bought the previously seen product (offer) at the reduced price (Sheng et al. 2007).

- Taking advantage of the previously seen deal will give me a sense of joy (Grewal et al. 1998).

- It is worth buying the mouse (and the keyboard) of the previously seen deal (Sheng et al. 2007).

- Buying the mouse (and the keyboard) of the previously seen deal is very economical (Yadav and Monroe 1993).

The phrasing for the different bundle conditions is shown in parentheses.

\section{Attribution}

- The quality of the mouse is inferior (Lichtenstein et al. 1989).

- The quality of the keyboard is inferior (Lichtenstein et al. 1989). ${ }^{9}$

- Sales of the mouse shall be stimulated (Lichtenstein et al. 1989).

\footnotetext{
9 This item is not shown in the control group and the condition where the mouse is offered individually for a reduced price.
} 
- The mouse is a remnant (new).

- To attract new customers (Lichtenstein et al. 1989).

- In the future, the mouse shall be offered for a reduced price anyway (new).

- To attempt to get customers into the store who also buy other products (Lichtenstein et al. 1989).

- The price of the mouse is supposed to meet competitor prices (Lichtenstein et al. 1989).

- There is no sufficient demand for the mouse (new).

- The price for the mouse was excessive before (new).

\section{Example of a Bundle Offer}

The bundle offer with the keyboard as price leader is basically identical, but the reduced price is shown with the keyboard (Fig. 2).

In the joint bundle offer, the price for in the circles close to both products is $20.99 €$. The text in the light blue box is replaced by "Buy together and save: $34.98 €$ instead of $41.98 €$ '. All other elements of the advertisement, including the text in the red stars and on the bottom, remain unchanged.

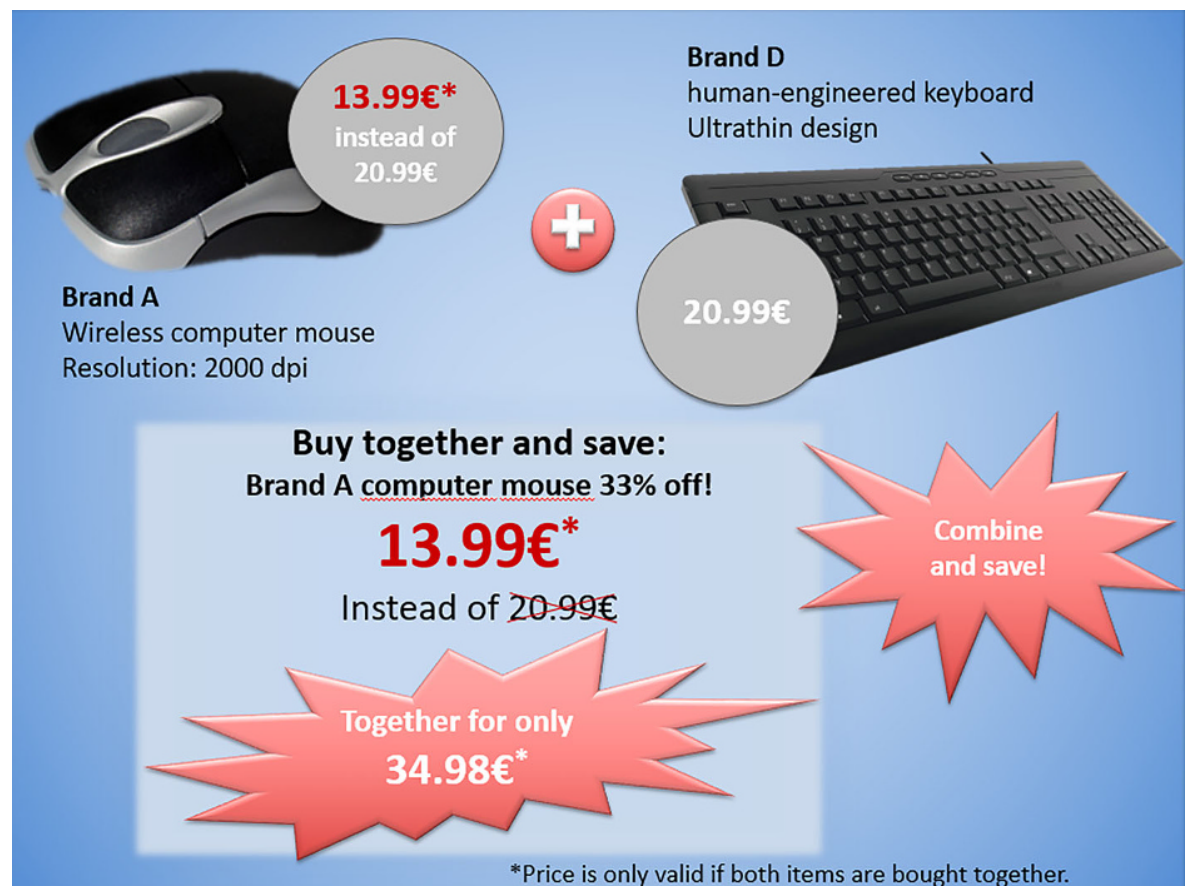

Fig. 2 Bundle offer with mouse as price leader (In the study, the real brand names Ednet (brand A) and Arctic (brand C) were used. The original advertisement was in German.) 


\section{References}

Adaval, R., and R.S. Wyer Jr. 2011. Conscious and nonconscious comparisons with price anchors: effects on willingness to pay for related and unrelated products. Journal of Marketing Research 48(2):355-365.

Blattberg, R.C., and S.A. Neslin. 1989. Sales promotion: the long and the short of it. Marketing Letters 1(1):81-97.

Blattberg, R.C., R. Briesch, and E.J. Fox. 1995. How promotions work. Marketing Science 14(3):G122G132.

Breidert, C., M. Hahsler, and T. Reutterer. 2006. A review of methods for measuring willingness-to-pay. Innovative Marketing 2(4):8-32.

DelVecchio, D., H.S. Krishnan, and D.C. Smith. 2007. Cents or percent? The effects of promotion framing on price expectations and choice. Journal of Marketing 71(3):158-170.

Diamond, W.D., and L. Campbell. 1989. The framing of sales promotions: effects on reference price change. Advances in consumer research 16(1):241-247.

Dodson, J.A., A.M. Tybout, and B. Sternthal. 1978. Impact of deals and deal retraction on brand switching. Journal of marketing research 15(1):72-81.

Estelami, H. 1999. Consumer savings in complementary product bundles. Journal of Marketing Theory and Practice 7(3):107-114.

Foubert, B., and E. Gijsbrechts. 2007. Shopper response to bundle promotions for packaged goods. Journal of Marketing Research 44(4):647-662.

Gedenk, K. 2002. Verkaufsförderung. München: Vahlen.

Gensler, S., O. Hinz, B. Skiera, and S. Theysohn. 2012. Willingness-to-pay estimation with choice-based conjoint analysis: addressing extreme response behavior with individually adapted designs. European Journal of Operational Research 219:368-378.

Gilbride, T.J., J.P. Guiltinan, and J.E. Urbany. 2008. Framing effects in mixed price bundling. Marketing Letters 19(2):125-139.

Grewal, D., K.B. Monroe, and R. Krishnan. 1998. The effects of price-comparison advertising on buyers' perceptions of acquisition value, transaction value, and behavioral intentions. Journal of Marketing 62(2):46-59.

Haaijer, R., W. Kamakura, and M. Wedel. 2001. The 'no-choice'alternative in conjoint choice experiments. International Journal of Market Research 43(1):93-106.

Harris, J., and E.A. Blair. 2012. Consumer processing of bundled prices: when do discounts matter? Journal of Product \& Brand Management 21(3):205-214.

Heeler, R.M., A. Nguyen, and C. Buff. 2007. Bundles= discount? Revisiting complex theories of bundle effects. Journal of Product \& Brand Management 16(7):492-500.

Janiszewski, C., and M. Cunha Jr. 2004. The influence of price discount framing on the evaluation of a product bundle. Journal of Consumer Research 30(4):534-546.

Johnson, M.D., A. Herrmann, and H.H. Bauer. 1999. The effects of price bundling on consumer evaluations of product offerings. International Journal of Research in Marketing 16(2):129-142.

Kaicker, A., W.O. Bearden, and K.C. Manning. 1995. Component versus bundle pricing: the role of selling price deviations from price expectations. Journal of Business Research 33(3):231-239.

Kalwani, M.U., and C.K. Yim. 1992. Consumer price and promotion expectations: an experimental study. Journal of Marketing Research 29(1):90-100.

Kamins, M.A., V.S. Folkes, and A. Fedorikhin. 2009. Promotional bundles and consumers' price judgments: when the best things in life are not free. Journal of Consumer Research 36(4):660-670.

Khan, U., and R. Dhar. 2010. Price-framing effects on the purchase of hedonic and utilitarian bundles. Journal of Marketing Research 47(6):1090-1099.

Krishna, A., R. Briesch, D.R. Lehmann, and H. Yuan. 2002. A meta-analysis of the impact of price presentation on perceived savings. Journal of Retailing 78(2):101-118.

Krishna, A., M. Wagner, C. Yoon, and R. Adaval. 2006. Effects of extreme-priced products on consumer reservation prices. Journal of Consumer Psychology 16(2):176-190.

Kwon, S., and S.S. Jang. 2011. Price bundling presentation and consumer's bundle choice: the role of quality certainty. International Journal of Hospitality Management 30(2):337-344.

Lenk, P.J., W.S. DeSarbo, P.E. Green, and M.R. Young. 1996. Hierarchical Bayes conjoint analysis: recovery of partworth heterogeneity from reduced experimental designs. Marketing Science 15(2):173-191.

Lichtenstein, D.R., and W.O. Bearden. 1986. Measurement and structure of Kelley's covariance theory. Journal of Consumer Research 13(2):290-296. 
Lichtenstein, D.R., S. Burton, and B.S. O'Hara. 1989. Marketplace attributions and consumer evaluations of discount claims. Psychology \& Marketing 6(3):163-180.

Mazumdar, T., and S.Y. Jun. 1993. Consumer evaluations of multiple versus single price change. Journal of Consumer Research 20(3):441-450.

McFadden, D. 1974. Conditional logit analysis of qualitative choice behaviour. In Frontiers of econometrics, ed. P. Zarembka, 105-142. New York: Academic Press.

Mela, C.F., S. Gupta, and D.R. Lehmann. 1997. The long-term impact of promotion and advertising on consumer brand choice. Journal of Marketing Research 34(2):248-261.

Mela, C.F., K. Jedidi, and D. Bowman. 1998. The long-term impact of promotions on consumer stockpiling behavior. Journal of Marketing Research 35(2):250-262.

Miller, K.M., R. Hofstetter, H. Krohmer, and J.Z. Zhang. 2011. How should consumers' willingness to pay be measured? An empirical comparison of state-of-the-art approaches. Journal of Marketing Research 48(2):172-184.

Munger, J.L., and D. Grewal. 2001. The effects of alternative price promotional methods on consumers' product evaluations and purchase intentions. Journal of Product \& Brand Management 10(3):185-197.

Nunes, J.C., and P. Boatwright. 2004. Incidental prices and their effect on willingness to pay. Journal of Marketing Research 41(4):457-466.

Nunnally, J.C. 1978. Psychometric theory, 2nd edn., New York: McGraw-Hill.

Nusair, K., H.J. Yoon, S. Naipaul, and H.G. Parsa. 2010. Effect of price discount frames and levels on consumers' perceptions in low-end service industries. International Journal of Contemporary Hospitality Management 22(6):814-835.

Palmeira, M.M., and J. Srivastava. 2013. Free offer $\neq$ cheap product: a selective accessibility account on the valuation of free offers. Journal of Consumer Research 40(4):644-656.

Raghubir, P. 2004. Free gift with purchase: promoting or discounting the brand? Journal of Consumer Psychology 14(1):181-186.

Raghubir, P. 2005. Framing a price bundle: the case of "buy/get" offers. Journal of Product \& Brand Management 14(2):123-128.

Raghubir, P., and K. Corfman. 1999. When do price promotions affect pretrial brand evaluations? Journal of Marketing Research 36(2):211-222.

Rossi, P.E., G.M. Allenby, and R. McCulloch. 2009. Bayesian statistics and marketing, 3rd edn., Chichester: John Wiley \& Sons.

Scarpa, R., M. Thiene, and K. Train. 2008. Utility in willingness to pay space: a tool to address confounding random scale effects in destination choice to the Alps. American Journal of Agricultural Economics 90(4):994-1010.

Schlereth, C., and B. Skiera. 2009. Schätzung von Zahlungsbereitschaftsintervallen mit der Choice-Based Conjoint-Analyse. Zeitschrift für betriebswirtschaftliche Forschung 61:838-856.

Sheng, S. 2006. Mixed-joint or mixed-leader bundle? The framing effects of price discount on bundle evaluations. Marketing Management Journal 16(2):125-136.

Sheng, S., A.M. Parker, and K. Nakamoto. 2007. The effects of price discount and product complementarity on consumer evaluations of bundle components. The Journal of Marketing Theory and Practice 15(1):53-64.

Sonnier, G., A. Ainslie, and T. Otter. 2007. Heterogeneity distributions of willingness-to-pay in choice models. Quantitative Marketing and Economics 5(3):313-331.

Stremersch, S., and G. Tellis. 2002. Strategic bundling of products and prices: a new synthesis for marketing. Journal of Marketing 66(1):55-72.

Thaler, R. 1985. Mental accounting and consumer choice. Marketing Science 4(3):199-214.

Urbany, J.E., W.O. Bearden, and D.C. Weilbaker. 1988. The effect of plausible and exaggerated reference prices on consumer perceptions and price search. Journal of Consumer Research 15(1):95-110.

Yadav, M.S. 1994. How buyers evaluate product bundles: a model of anchoring and adjustment. Journal of Consumer Research 21(2):342-353.

Yadav, M., and K. Monroe. 1993. How buyers perceive savings in a bundle price: an examination of a bundle's transaction value. Journal of Marketing Research 30(3):350-358.

Publisher's Note Springer Nature remains neutral with regard to jurisdictional claims in published maps and institutional affiliations. 